\title{
Integrated management framework for sustainable cities: insights into multiple concepts and principles
}

\author{
K. G. Baffour Awuah \& C. A. Booth \\ Construction and Property Research Centre, \\ University of the West of England, UK
}

\begin{abstract}
There is a growing call for cities and the built environment to be managed or remanaged based on the idea of sustainability. The rationale is to make cities more resilient and productive as centres of production and consumption, and address the rising environmental and socio-cultural challenges associated with twenty-first century urban centres. There are, however, emerging or extant concepts that attempt to supplant or espouse sustainability principles or related principles; thereby, creating a seemingly unclear framework to drive effective and efficient management of cities. Through interrogation of extant literature, this study identifies four main neighbouring concepts - industrial ecology, natural capitalism, cradle-to-cradle and circular economy and how they compare and contrast with sustainability in the context of the built environment. Despite the seemingly conceptual difference between sustainability and the neighbouring concepts, they prescribe virtually the same set of principles and operationalisation indicators. However, given the multiplicity of the concepts, their set of principles and indicators, and uniqueness of different cities, an initial broad integrated framework needs to be developed based on all the concepts. Subsequently, individual cities taking cognisance of their peculiar circumstances will then have to craft their own frameworks for effective and efficient management in the face of growing economic uncertainties, poverty, rapid urbanisation and other environmental and socio-cultural challenges.

Keywords: cities, economic uncertainties, environment, strategy, sustainability.
\end{abstract}




\section{Introduction}

It is now a widely accepted hypothesis that cities hold the key to the world's prosperity [1]. Cities and urban areas in the global south are experiencing rapid urbanisation while their counterparts in the global north, which had long experienced the phenomenon, are becoming centres of intense re-urbanisation [2]. More than $50 \%$ of the world's population has been living in urban areas since 2008 and this is expected to increase to about $70 \%$ by 2050 [3]. Although much of this growth is predicted to occur in developing economies particularly those of subSaharan Africa (SSA) and Asia [4] cities in the developed economies such as the USA, UK, Germany, Italy and Japan are still undergoing intensive growth [5].

Agglomeration economics posits that concentration of people and economic activities (city growth) through advantages such as reduction in inputs and transportation cost, creation of large market size, knowledge sharing, innovation and information externalities promote economic growth [6]. Evidence also suggests that $80 \%$ of the global GDP are generated by cities [7]. Nevertheless, this economic prosperity has not been even. Furthermore, it has often been pursued at the expense of social, cultural, environmental and other development imperatives [1]. For example, cities occupy about $2-3 \%$ of the earth surface, but generate about $75 \%$ of the earth's waste [4]. Cities in the world today are confronted with several problems and challenges such as climate change, environmental pollution and degradation, social injustices, spatial segregation, unemployment, poverty, traffic congestion, and urban sprawl and fragmentation $[1,5,8]$. Therefore, although engine of growth and development in the twenty-first century, cities need to demonstrate balanced developments and resilience through effective and efficient management.

Sustainability principles are widely offered for effective and efficient management and re-management of twenty-first century cities and urban areas [1, $2,9]$. However, similar and related principles have been and are being proposed by existing and emerging neighbouring concepts such as industrial ecology, natural capitalism and cradle-to-cradle. It is, thus, unclear which concepts and principles should drive effective and efficient management of cities in the twentyfirst century. This study through a critique of the relevant literature aims to identify the main neighbouring concepts to the sustainability concept, their principles and how they compare and contrast with sustainability principles in the context of effective and efficient management of cities and the built environment. It is argued that given the multiplicity of concepts and principles, an integrated framework with appropriate holistic set of principles to drive effective and efficient management of cities is vital. To address the aim of this study, the next section will discuss the concept of city, sustainability and sustainable city -principles. Following this, the main neighbouring concepts and their principles as applied to the built environment will be discussed. A further discussion comparing and contrasting sustainable city principles and those of the neighbouring concepts will be undertaken before conclusions are drawn. 


\section{City, sustainability and sustainable city}

Conceptually, cities appear as accretion of humans and human activities [10]. This accretion of humans and human (anthropogenic) activities is comparatively substantially higher than other places such as the rural areas or the countryside [10-12]. The anthropogenic activities also comprise activities such as economic, social, cultural and educational. Since cities attract more humans and anthropogenic activities as they grow, their natural and biological elements tend to suffer reducing them to a very small amount. Consequently, cities depend predominantly on surrounding eco-system(s) to support the natural and biological functions relevant to them [13]. To this extent, they are characteristically seen as replacement of the human and social organisation structure, which is premised on human - nature relationship and the construction of a structure premised on human - human relationship. Furthermore, production procedure in cities from the economic standpoint is based on social organisation, capital, energy and information compared to rural areas where it is based on land and labour [10].

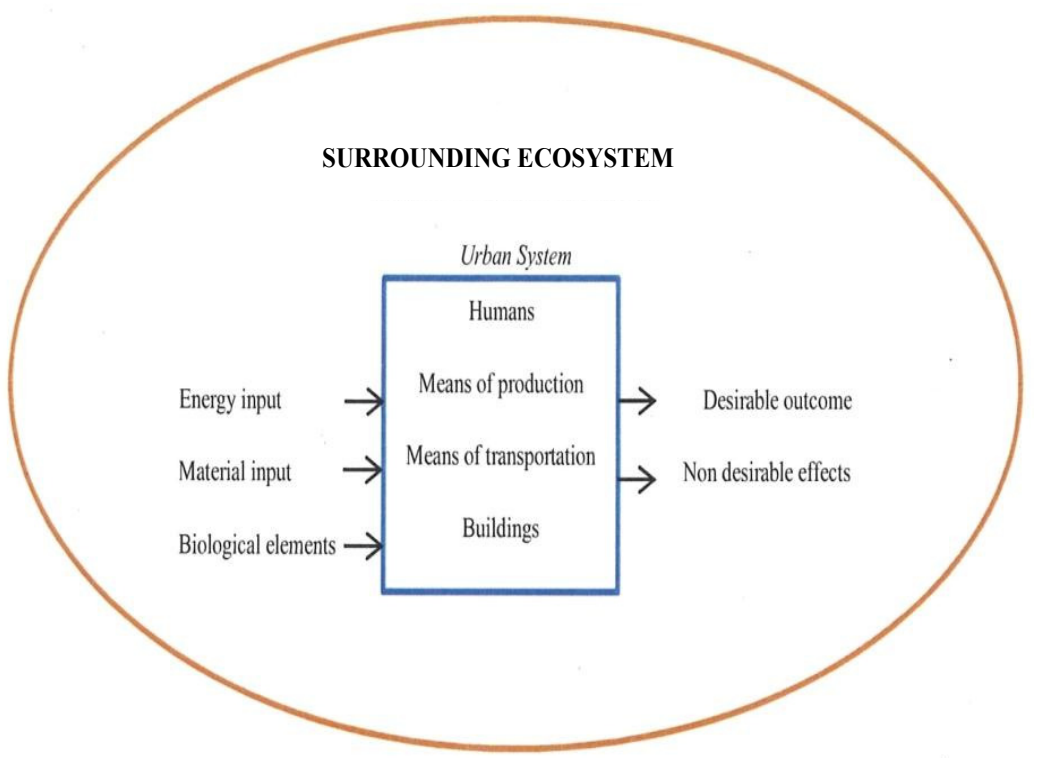

Figure 1: The city physiology. (Source: Bithas and Christofakis [10].)

According to Bithas and Christofakis [10] history suggests that cities have contributed in a unique way to the pursuit of social and economic objectives of humankind. Cities increase the efficiency of the achievement of individual and social objectives. They also create new objectives and social targets, procedures and patterns in the economic, social and political fields for growth and development of societies based on dynamic evolution of social procedures and combination of existing economic and social forces [6;10, p. 181]. However, 
as pointed out previously and demonstrated by Figure 1, these desirable functions of cities stem from the accumulation of humans and their activities and the natural and biological elements mainly from the countryside that support them. This creates inter-linkages between cities and their countryside. The accumulation also creates non-desirable outcomes (Figure 1). These include: urban crime, waste, atmospheric pollution, traffic congestion, social alienation and urban sprawl and slums $[5,8,14]$. For example, buildings are said to account for $40 \%$ of global annual energy consumption and are responsible for one-third of humanity's resource consumption [15]. They also generate up to $40 \%$ of all solid waste and contribute a third of all energy related $\mathrm{CO}_{2}$ emissions and a third of global greenhouse gases [16]. Over 1 billion of the world's population also live in urban slums with no water or sanitation [8].

It is to address the non-desirable effects of cities that efforts are being made to develop and manage them based on sustainability principles - sustainable cities [17-19]. The European Campaign of Sustainable Cities and Towns and the 'Healthy cities' idea through which ways are being sought by local governments in more than 1000 cities to collaborate and work with different actors and stakeholders within their frontiers to promote health and prevent diseases are examples of such efforts. More recently, the UN-Habitat has developed the City Prosperity Index together with a conceptual matrix known as the Wheel of Urban Prosperity to assist decision makers to devise clear policy interventions based on economic, social, cultural and political considerations among others to ensure effective and efficient functioning of cities to promote prosperity [1].

The idea of sustainability and sustainable cities is traceable to the concept of sustainable development, which begun to gain prominence pursuant to the publication of the World Commission on Environment and Development; the Brundtland Commission titled: Our Common Future in 1987. The Brundtland Commission defines sustainable development as development that meets the needs of present generation without compromising the ability of future generations to meet their own needs. Following this publication by the Brundtland Commission, sustainable development has been interpreted in several ways and applied in numerous fields of endeavour [8, 20, 21]. However, according to Stahel [22] sustainable development and by extension sustainability is based on economic, ecological and social/cultural pillars, and forms a dynamic balancing by which society exploits the environment, create wealth and fulfil social needs.

As applied to cities, sustainability is seen as creating livable cities that reconcile the conflicts among economic development, ecological preservation and intergenerational equity [9]. However, there seem to be a lack of consensus on the operational definition or meaning of sustainable cities [17-19, 23, 24]. Guy and Marvin [23], for example, underscored the multiplicity of studies, which have conceived the idea of sustainable cities as a singular technocratic vision with a set of pre-defined assumptions although the concept transcend beyond that. Jabareen [24] also argues that there is often lack of a theoretical framework within which cities may be evaluated as to the extent of their achievement of sustainability status. Nonetheless, a number of principles of sustainable cities are apparent in the literature. 
The principles are usually expressed within the main pillars of sustainability; economic, social and environmental (ecological) although the economic and social principles tend to be under-emphasised [25]. Table 1 summarises the principles. The inter-relationships between the three main principles are among others to ensure increase in production efficiency and value, create opportunities for social networking among individual city dwellers and promote access to amenities while at the same time make the physical environment healthy through, for example, clean air, water and promotion of urban greenery for conducive and peaceful social living [25]. Thus, the ultimate aim of these principles is to achieve sustainability - sustainable development. The principles are further discussed with principles of the neighbouring concepts later in section 4.

Table 1: $\quad$ Sustainable city principles. (Source: adapted from $[25,26]$.)

\begin{tabular}{ll|}
\hline Economic: & $\begin{array}{l}\text { Efficient use of resources - energy and non-renewable natural resources; and } \\
\text { promotion of economies of scale in the use of urban environmental amenities. }\end{array}$ \\
Social: & $\begin{array}{l}\text { Accessibility to suitable housing and jobs, social amenities, social contacts, } \\
\text { education facilities, health services and urban environmental facilities; ability to } \\
\text { diversify options; avoidance of forced sub-urbanisation due to high urban rents } \\
\text { and social friction on the labour market; prevention of new poverties; and } \\
\text { preservation of urban health, human rights, democracy, dignity, cultural heritage } \\
\text { and historic buildings etc. }\end{array}$ \\
Environmental: & $\begin{array}{l}\text { Reduction of waste; avoidance of depletion of natural resource and green areas, } \\
\text { and intensive energy use; prevention of water, air and noise pollution, and traffic } \\
\text { congestion; promotion of biodiversity and aesthetics. }\end{array}$ \\
\hline
\end{tabular}

\section{Neighbouring concepts}

There are several existing and emerging concepts that espouse similar or related principles to those of sustainability principles [27]. The concepts include biomimicry, positive development, industrial ecology, natural capitalism, cradleto-cradle, circular economy and performance economy. This paper focuses on industrial ecology, natural capitalism, cradle-to-cradle and circular economy due to the seemingly increasingly popularity of these concepts.

\subsection{Industrial Ecology (IE)}

The concept of industrial ecology is often traced to the work of Frosch and Gallopoulos (1989) on Strategies for Manufacturing [28, 29]. Although its principal focus is industrial symbiosis [29] it is rooted in ecologist philosophy of carrying capacity- human carrying capacity. This is conceived as the maximum amount of resource consumption and waste discharge that can be sustained indefinitely without progressively destroying the functional integrity and productivity of the relevant eco-system [30]. The concept like how the natural ecosystem functions, seeks to promote interdependence in an industrial system where one firm's waste becomes another's input through systems design of production processes taking into account material and energy flow and their global 
environmental impact to prevent or reduce waste [29-31]. It emphasises closedloop production system. The idea is that industrial or anthropogenic -economic and social activities and the physical environment are not independent of each other. The concept, thus, espouses the need for efficient production system to increase production, reduce cost, protect the environment and promote social gains such as employment and diversified local economy [29, 31]. Apart from this, it posits minimisation of resource and energy consumption and the promotion of networking and cluster building [27]. Like sustainability principles, principles of the concept as applied to cities aim in a systematic way to design, develop and manage cities as theatres of production and consumption to increase production, reduce cost and prevent or reduce adverse environmental footprint while promoting socio-cultural harmony.

\subsection{Natural Capitalism (NC)}

The central focus of natural capitalism seems to dwell on ecological preservation; however, it has economic and social dimensions. According to Lovins [32] the foundation of natural capitalism is to attain human needs in ways that achieve durable competitive advantage, address most of the environmental and social challenges that confront the world at a profit and ensure higher quality of life for all people. It posits that the most valuable capital of humankind is the ecosystem - natural capital, and like the other concepts recognises the inter-dependency between production, the use of human-made capital and the need for maintenance and supply of natural capital [33]. Lovins et al. [34] outline four broad principles of natural capitalism production system. These are: increase the productivity of natural resources - achieving more from minimal resources through reduction of depletion and wasteful use of resources; movement beyond waste reduction to waste elimination through biological design based on how the eco-system functions - a closed loop production model where every output is returned harmlessly to the ecosystem as nutrient or becomes input for the production of another product; movement to a new business model that deliver value as flow of services rather than the traditional sale of goods; and re-investment in natural capital - the need for businesses to restore, sustain and expand the earth's ecosystem to ensure its continuous supply of vital services and biological resources.

As applied to cities, Hawken et al. [33] conceptualised cities designed, developed and managed based on natural capitalism principles to be, for example, peaceful and serene because: vehicles whisper quiet and exhaust water vapour; parks and greenways have taken over urban freeways; there is less use of fossil fuel and dependence on better energy sources; improvement in standard of living of urban residents especially the poor; improved access to decent housing; and non-existence of unemployment among others.

\subsection{Cradle-to-cradle (C2C)}

$\mathrm{C} 2 \mathrm{C}$ is an emerging concept. Its development is mostly attributed to Michael Braungart and William McDonough $[35,36]$. The concept is described as a 
paradigm changing platform for designing beneficial economic, social and environmental features into products, process and systems [35]. It, thus, subscribes to an initial intelligent design that allows creation and implementation of wholly beneficial industrial systems driven by synergistic pursuit of positive economic, ecological and social goals based on eco-effective philosophy [37]. Three pathways define the concept. These are: waste equals food; the use of current solar income; and celebration of diversity. The idea of waste equals food is to create a continuous closed loop production system where everything is a nutrient for something else - input for the manufacture of another product. To achieve this, the concept envisages two distinct metabolisms (production systems) - technical and biological. The biological metabolism is to be designed for biological processes with biodegradable materials, which are useful but not harmful to human beings and other living systems. The by-product of this process is expected to be returned safely into the ecosystem in continuation of the biological process. The technical metabolism is to be designed for technical service whose materials potentially harmful to human beings and other living systems are supposed to be continuously recycled for use. However, so long as the materials remain in the closed loop technical metabolism they are expected to pose no harm to living systems. Although the concept acknowledges efficiency, it does not subscribe to limitation to the use of resources. As such, resources are not supposed to be exploited to their elastic limits to destroy their quality prior to recycling and reuse. The use of current solar income emphasises the use of solar and renewable energy rather than reliance on fossil fuel and other non-renewal energy sources. Celebration of diversity focuses on the need to promote innovation to manufacture different types of products, and integration among others.

In the context of the built environment, McDonough and Braungart [38, p. 13] define it as: "........an ecologically intelligent approach to architecture and industry that involves materials, buildings and patterns of settlement which are wholly healthy and restorative." Mulhall and Braungart [35, p. 7] also state that: "A cradle-to-cradle building contains defined elements that add value and celebrate innovation and enjoyment by: measurably enhancing the quality of materials, biodiversity, air and water; using current solar income; being deconstructible and recyclable; and performing diverse practical and lifeenhancing functions for its stakeholders". Other studies such as [39] liken C2C cities to forests with the trees therein as buildings, and are expected to promote positive economic, socio-cultural and ecological objectives.

\subsection{Circular Economy (CE)}

Circular economy is a development strategy, which maximises resource efficiency and eliminates waste production [40]. The concept is often seen as a combination of several thoughts or strategies. Therefore, it is difficult to attribute its development to a particular author(s) [31]. The concept is explained to mean an industrial economy, which is restorative [31]. Like the $\mathrm{C} 2 \mathrm{C}$ concept, it is based on an initial intelligent design through systems thinking and material and energy flow of closed loop production systems or processes; biological and technical that seek to prevent waste. It, thus, subscribes to the waste equals food principle. The 
concept also promotes the use of renewable energy as against non-renewable and diverse product and process approaches. Also like natural capitalism, circular economy additionally seeks to rebuild capital both natural and social. It, therefore, in an integrative manner aims to achieve positive economic, socio-cultural and ecological goals. Consequently, from the standpoint of cities as centres of production and consumption, the idea is to design, develop and manage them based eco-effective philosophy to achieve economic growth, socio-cultural harmony and positive ecological foot print.

\section{Discussions}

Comparatively, sustainability principles have received wide application in the design, development and management of the built environment - cities. Application of the principles of industrial ecology has mostly been in the area of eco-industrial parks (EIP) or business parks [28]. Those of natural capitalism, C2C and circular economy at best can be described as rudimentary. For $\mathrm{C} 2 \mathrm{C}$, the continuous work by the $\mathrm{C} 2 \mathrm{C}$ Network in Europe, and others such as McDonough and $[35,38]$ in this regard are gaining prominence. As argued earlier (section 2), the ultimate aim of the application of sustainability principles is to achieve sustainable development. To achieve this goal, the World Business Council for Sustainable Development (WBSCD) in 1992 prescribed eco-efficiency strategy in its publication 'changing course' [32]. This strategy, therefore, dictated sustainability principles and emphasised: a reduction in the material intensity of goods or services; a reduction in the energy intensity of goods or services; reduced dispersion of toxic materials; improved recyclability; maximum use of renewable resources; greater durability of products; and increased service intensity of goods and services. Thus, cities and their activities must be designed, developed and managed based on these principles among others to achieve sustainability. Conceptually, however, these sustainability principles differ from what the other neighbouring concepts stand for, which is based on eco-effective philosophy and seek to design and manage cities and their activities to eliminate the concept of waste through intelligent design of distinct biological and technical production systems where everything is resource for something else. The neighbouring concepts also do not emphasise limitation of resource use although they subscribe to resource efficiency.

Nonetheless, sustainability principles have grown to encompass principles of the neighbouring concepts [www.product-life.org]. Gibbs and Deutz [29], for example, describe industrial ecology as the science of sustainability. Lovins [32] also argues that the basis of sustainability is natural capitalism while Ellen McAuthur Foundation [31] acknowledges that the neighbouring concepts are central to the achievement of sustainability. It will appear that the acceptance of WBCSD eco-efficiency principles as part of drivers for sustainability was informed by practical considerations of the current state of the world's knowledge and technology to deliver eco-effective solutions. Indeed, the first principle of natural capitalism accepts these eco-efficiency principles as an initial step to deliver eco-effective solutions. It, thus, seems that both sustainability and its 
neighbouring concepts' principles in the context of the built environment and city management appear to preach the same or similar principles although protagonists of $\mathrm{C} 2 \mathrm{C}$ such as Braungart et al. [37] and Mulhall and Braungart [35] continue to argue for a distinction between $\mathrm{C} 2 \mathrm{C}$ and sustainability. However, this seemingly relatedness of the principles of all the concepts becomes somewhat apparent at the operationalisation stage of the principles in the built environment.

Table 2: Matrix of indicators of sustainability and neighbouring concepts' principles. (Source: constructed from literature review.)

\begin{tabular}{|c|c|c|c|c|c|}
\hline Element options & Sustainability & C2C & NC & IE & CE \\
\hline Wealth creation & $\sqrt{ }$ & $\sqrt{ }$ & $\sqrt{ }$ & $\sqrt{ }$ & $\sqrt{ }$ \\
\hline Efficient resource use & $\sqrt{ }$ & $\sqrt{ }$ & $\sqrt{ }$ & $\sqrt{ }$ & $\sqrt{ }$ \\
\hline Land use intensity & $\sqrt{ }$ & $\sqrt{ }$ & $\sqrt{ }$ & $\sqrt{ }$ & $\sqrt{ }$ \\
\hline Communal use of resources & $\sqrt{ }$ & $\sqrt{ }$ & $\sqrt{ }$ & $\sqrt{ }$ & $\sqrt{ }$ \\
\hline Employment generation & $\sqrt{ }$ & $\sqrt{ }$ & $\sqrt{ }$ & $\sqrt{ }$ & $\sqrt{ }$ \\
\hline Access to decent housing & $\sqrt{ }$ & $\sqrt{ }$ & $\sqrt{ }$ & $\sqrt{ }$ & $\sqrt{ }$ \\
\hline Poverty reduction & $\sqrt{ }$ & $\sqrt{ }$ & $\sqrt{ }$ & $\sqrt{ }$ & $\sqrt{ }$ \\
\hline Equity & $\sqrt{ }$ & $\sqrt{ }$ & $\sqrt{ }$ & $\sqrt{ }$ & $\sqrt{ }$ \\
\hline Social integration & $\sqrt{ }$ & $\sqrt{ }$ & $\sqrt{ }$ & $\sqrt{ }$ & $\sqrt{ }$ \\
\hline Biodiversity integration & $\sqrt{ }$ & $\sqrt{ }$ & $\sqrt{ }$ & $\sqrt{ }$ & $\sqrt{ }$ \\
\hline Architectural design diversity & $\sqrt{ }$ & $\sqrt{ }$ & $\sqrt{ }$ & $\sqrt{ }$ \\
\hline Land use design diversity & $\sqrt{ }$ & $\sqrt{ }$ & $\sqrt{ }$ & $\sqrt{ }$ & $\sqrt{ }$ \\
\hline Piverse mode of transportation & $\sqrt{ }$ & $\sqrt{ }$ & $\sqrt{ }$ & $\sqrt{ }$ & $\sqrt{ }$ \\
\hline Preservcle and reuse of materials & $\sqrt{ }$ & $\sqrt{ }$ & $\sqrt{ }$ & $\sqrt{ }$ \\
\hline Solar and renewable energy & $\sqrt{ }$ & $\sqrt{ }$ & $\sqrt{ }$ & $\sqrt{ }$ & $\sqrt{ }$ \\
\hline Health and environmental enriching & $\sqrt{ }$ & $\sqrt{ }$ & $\sqrt{ }$ & $\sqrt{ }$ & $\sqrt{ }$ \\
\hline materials & $\sqrt{ }$ & $\sqrt{ }$ & $\sqrt{ }$ & $\sqrt{ }$ & $\sqrt{ }$ \\
\hline Water cleansing feature & $\sqrt{ }$ & $\sqrt{ }$ & $\sqrt{ }$ & $\sqrt{ }$ & $\sqrt{ }$ \\
\hline Water protection feature & $\sqrt{ }$ & $\sqrt{ }$ & $\sqrt{ }$ & $\sqrt{ }$ \\
\hline Water recycling and re-use & $\sqrt{ }$ & $\sqrt{ }$ & $\sqrt{ }$ & $\sqrt{ }$ \\
\hline Co-operation & & & & \\
\hline Innovation & $\sqrt{ }$ & & & & \\
\hline
\end{tabular}

Although the list of operationalisation indicators (Table 2) provided in this paper is by no means exhaustive, a comprehensive scan of the literature shows that all the concepts expect cities to be productive. In so doing, they promote the use of efficient production processes and products, and efficient use of resources and energy to reduce cost and increase the wealth (GDP) that cities create. The concepts see these in, for example, design of cities for intensive land use. In the sustainability literature, this is often pursued through the 'compact city' agenda. The idea is to reduce energy consumption and emissions of greenhouse gases among others through reduction in travel distance, and contain urban sprawl. A further way of promoting efficiency by all the concepts is through the use of energy efficient materials such as bulbs, the orientation of buildings to enable the use of day light, the promotion of communal use of resources like public transport, the use common car park, and water and energy sources especially in business parks. These could also lead to social integration in cities. Cities are not only supposed to increase GDP growth, but also to ensure that the process leading to the growth and the growth itself should result in welfare of the different socioeconomic groups according to all the concepts. All the concepts, thus, recommend 
proxies such as increase in employment opportunities, reduction in poverty, access to decent housing and equity in access to public and social amenities.

Furthermore, all the concepts also interpret the welfare in terms of the nature of the physical environment and its diversity, and social integration. They therefore recommend proxies such as aesthetic urban developments integrated with biodiversity - urban space with greenery, individual developments with landscape, acquaponics, trees; design of individual developments for multiple uses and suitable to the use of multiple energy sources; preservation of historical buildings; mixed land utilisations which allow for multiple or diverse mode of transportation - walking and cycling among others; and urban development that is inclusive of all socio-economic groups. This is said to ensure safety even against effects of climate and environmental change, and reduction in social exclusion. To eliminate the concept of waste and promote positive environment foot print, all the concepts suggest the design of urban developments that allow for disassemble of physical developments for re-use, and the use of solar walls and roof panels, photovoltaic, biogas, geothermal plants and smart grids. They also recommend the use of health and environmental enhancing materials that clean and purify air (indoor and outdoor) and water quality like green doors, walls, windows and roofs as well as materials that are adaptive to effects of climate and environment change. Besides, they recommend harvesting and recycling of water for use. Additionally, they all propose a co-operative approach to urban management where all stakeholders need to be consulted and are expected to collaborate to develop urban governance protocols and work with them to achieve success. Last but not the least, all the concepts recognise that innovation holds the key to the achievement of all the indicators and, therefore, they recommend continuous research and education to underpin efforts to realise their visions.

\section{Conclusions}

Cities are central to the world's quest to achieve prosperity and socio-economic progress. Cities produce much of the globe's output and have the largest share of its population although they occupy comparatively small portion of the earth surface. However, the continuous reliance of the world on the linear site development system and the ways cities have functioned and operated over the years has rather led to unpleasant socio-economic and ecological effects notably threats to future resource security and human health, environmental degradation, and economic and social deprivation. It is argued that, if these adverse effects are not addressed through effective and efficient management of cities they could potentially derail contributions that cities make to socio-economic progress. Consequently, management of cities based on sustainability principles has been proposed. There are also extant and emerging neighbouring concepts that prescribe similar and related principles, which advocates suggest that they could deliver effective and efficient management of cities in the twenty first century.

This study set out to examine the differences and similarities of the sustainability concept and four neighbouring concepts namely: industrial ecology; natural capitalism; $\mathrm{C} 2 \mathrm{C}$ and the circular economy in the context of effective and 
efficient management of cities. Like the sustainability concept, the study establishes that the neighbouring concepts dwell on principles that foster the right balance between ensuring that cities continue to be productive to create wealth, maintain positive environmental foot print and socio-cultural harmony. Conversely, unlike the sustainability concept, which is based on eco-efficiency principles that emphasise increase in economic output and a decrease in the impact of economic activities on the ecosystem, the neighbouring concepts are driven by eco-effective philosophy, which among others promotes resource efficiency based how nature functions. Nonetheless, it will appear that sustainability principles have grown to incorporate eco-effective principles. Therefore, at the operationalisation of the principles level, all the concepts seem to propose same or similar indicators for effective and efficient management of cities. The foregoing notwithstanding, a number of these indicators are difficult if not impossible to achieve given the current state of the world's technology. Perhaps it is because of this that all the concepts emphasise innovation based on continuous research and education. Besides, these concepts, their principles and indicators are numerous and could be complex. Policy makers and implementers such as city managers may, thus, potentially be prone to misunderstand them and misjudge their application. Furthermore, to reiterate Jabareen [24] cities are also different - they have unique strengths and weakness, and are confronted with different challenges. For example, cities in the global south are different from those of the global north in terms of their current challenges, potentials, endowments and abilities. Therefore, to address the challenges that confront twenty-first century cities there is a need for a broad overall integrated framework to be developed for effective and efficient management of cities based on sustainability and all its neighbouring concepts. Following on from this, individual cities based on their peculiar circumstances will then have to craft their own frameworks to drive effective and efficient management.

\section{References}

[1] UN-Habitat, State of the world's cities 2012/2013. Prosperity of cities, London: Earthscan, 2013.

[2] UN-Habitat, Planning sustainable cities: policy directions. Global report on human settlements, London: Earthscan, 2009.

[3] Baffour Awuah, K.G., Hammond, F.N., Lamond, J.E. and Booth, C., Benefits of urban land use planning in Ghana, Geoforum 51, pp. 37-46, 2014a.

[4] Hammond, F.N., Baffour Awuah, K.G. and Adiaba, S., Urbanisation and climate change. In: Booth, C.A., Hammond, F.N., Lamond, J.E. and Proverbs, D.G. (Eds.) Solutions to climate change challenges for the built environment, Oxford: Wiley Black Wells, 2012.

[5] Brown, A., Challenges of development and undevelopment in a globalising world. In: Campagna, M., De Montis, A., Isola, F., Lai, S., Pira, C. and Zoppi, C. (Eds.) Planning support tools: policy analysis, implementation and evaluation, Proceedings of the Seventh International Conference on 
Informatics and Urban and Regional Planning INPUT 2012, Milan: Franco Angeli, 2012.

[6] Glaeser, E.L, Learning in cities, Journal of Urban Economics, 46(2), pp. 254-277, 1999.

[7] Mckinsey Global Institute, Urban world: cities and the rise of the consuming class, available from: http://www.mckinsey.com/mgl [Accessed: August 2012], 2012.

[8] Baffour Awuah, K.G., Hammond, F.N., Booth, C. and Lamond, J.E., Evolution and development of urban land use planning: analysis from human action perspective. Theoretical and Empirical Researches in Urban Management 9(2), pp. 35-67, 2014b.

[9] Godschalk, D.R., Land use planning challenges: coping with conflicts in visions of sustainable development and liveable communities, Journal of the American Planning Association, 70(1), pp. 5-13, 2004.

[10] Bithas, K.P. and Christofakis, M., Environmentally sustainable cities, critical review and operational conditions, Sustainable Development, 14, pp. 177-189, 2006.

[11] Frey, W.H. and Zimmer, Z., Defining the city. In: Paddison, R. (Ed.) Handbook of urban studies, London: SAGE Publications, 2001.

[12] Oduro, C.Y., Effects of rapid urbanisation on livelihoods in the peri-urban areas of Accra, Ghana, Unpublished PhD Thesis, Florida State University, USA, 2010.

[13] Bryant, C.R., Russwurm, L.H. and McLellan, A.G., The city's countryside. Land and its management in the rural-urban fringe, London: Longman, 1982.

[14] Hirsch, W.Z., Urban economic analysis, New York: McGraw-Hill Book Company, 1973.

[15] UNEP, Buildings: investing in energy and resource efficiency, New York: $\mathrm{UN}, 2011$.

[16] UNEP-SBCI, Buildings and climate change, New York: UN, 2011.

[17] Satterthwaite, D., Sustainable cities or cities that contribute to sustainable development? Urban Studies, 34(10), pp. 1667-1691, 1997.

[18] Bulkeley, H. and Betsill, M., Rethinking sustainable cities: multilevel governance and the 'urban' politics of climate change. Environmental Politics, 14(1), pp. 42-63, 2005.

[19] Milutinovic, S. and Jolovic, N., Building capacity for sustainability: strategic planning processes for sustainable development practices in Western Balkan, Journal of Local Self Government, 8(3), pp. 293-311, 2010 .

[20] William, C.C. and Millington, A.C., The diverse and contested meanings of sustainable development, The Geographical Journal, 170(2), pp. 99-104, 2004.

[21] Redclift, M., Sustainable development (1987-2005): an oxymoron comes of Age, Sustainable Development, 13(4), pp. 212-227, 2005.

[22] Stahel, W.R., The virtuous circle? Sustainable economics and taxation in a time of austerity, Think piece, 63, 1-6, 2011. 
[23] Guy, S. and Marvin, S., Understanding sustainable cities: competing urban futures, European Urban and Regional Studies, 6(3), pp. 268-275, 1999.

[24] Jabareen, Y.R., Sustainable urban forms, their typologies, models, and concepts, Journal of Planning Education and Research, 26, pp. 38-52, 2006.

[25] Camagni, R., Capello, R. and Nijkamp, P., Towards sustainable city policy: an economy-environment technology nexus, Ecological Economics, 24, pp. 103-118, 1998.

[26] Coaffee, J., Risk, resilience, and environmentally sustainable cities, Energy Policy, 36, pp. 4633-4638, 2008.

[27] Edwards, A.R., The sustainability revolution: portrait of a paradigm shift, Gabriola Island, BC: New Society Publishers, 2005.

[28] Heers, R.R., Vermeulen, W.J.V. and de Walle, F.B., Eco-industrial park initiatives in the USA and the Netherlands: first Lessons, Journal of Cleaner Production, 12, pp. 985-995, 2004.

[29] Gibbs, D. and Deutz, P., Reflections on implementing industrial ecology through eco-industrial park development, Journal of Cleaner Production, 15, pp. 1683-1695, 2007.

[30] Lowe, E.A. and Evans, L.K., Industrial ecology and industrial ecosystems. Journal of Cleaner Production, 3(1-2), pp. 47-53, 1995.

[31] Ellen MacArthur Foundation, Towards the circular economy: economic and business rationale for an accelerated transition, available from: http://www.ellenmacarthurfoundation.org/circular-economy/circulareconomy/towards-the-circular-economy [Accessed: February 2013], 2012.

[32] Lovins, L.H., Rethinking production. State of the world innovations for a sustainable economy, New York: The World Watch Institute, 2008.

[33] Hawken, P., Lovins, A. and Lovins, L.H. (2010). Natural capitalism: the next industrial revolution. London: Earthscan.

[34] Lovins, A.B., Lovins, L.H. and Hawken, P., A road map for natural capitalism, Harvard Business Review, pp. 145-158, 1999.

[35] Mulhall, D. and Braungart, M., Cradle-to-cradle criteria for the built environment, The Netherlands: EPEA Internationale Umweltforschung $\mathrm{GmbH}, 2010$.

[36] Iosif-Lazar, L.C., The evolution of the cradle-to-cradle model implementation within organizations, MSc Dissertation, Copenhagen Business School, Copenhagen, 2012.

[37] Braungart, M., McDonough, W. and Bollinger, A., Cradle-to-cradle design: creating healthy emissions - a strategy for eco-effective product and system design, Journal of Cleaner Production, 15, pp. 1337-1348, 2007.

[38] McDonough, W. and Braungart, M., Towards a sustaining architecture for the $21^{\text {st }}$ century: the promise of cradle-to-cradle, Sustainable Building and Construction, pp. 13-16, 2007.

[39] Out, P., Levels, P., Albering, H. and Ouwehand, B., Perspective study: area spatial development, Cologno Monzese, Italy: Gruppo Stampa GB, 2010.

[40] Hislop, H. and Hill, J., Reinventing the wheel: a circular economy for resource security, London: Green Alliance, 2011. 